\title{
Participatory Evaluation of the Relative Livestock Populations and the Assessment of the Status and Impacts of Newcastle Disease in Rural Communities of Two Northeastern States, Nigeria
}

\author{
Waziri Ibrahim Musa1* ${ }^{*}$, Sa'idu Lawal'2, Mohammed Bello³ , Paul Ayuba Abdu1 \\ ${ }^{1}$ Department of Veterinary Medicine, Ahmadu Bello University, Zaria, Nigeria \\ ${ }^{2}$ Veterinary Teaching Hospital, Ahmadu Bello University, Zaria, Nigeria \\ ${ }^{3}$ Department of Veterinary Public Health and Preventive Medicine, Ahmadu Bello University, Zaria, Nigeria \\ Email: “ibwazkalt@yahoo.co.uk,iwmusa@abu.edu.ng
}

Received 10 December 2015; accepted 15 January 2016; published 18 January 2016

Copyright (C) 2016 by authors and Scientific Research Publishing Inc.

This work is licensed under the Creative Commons Attribution International License (CC BY). http://creativecommons.org/licenses/by/4.0/

(c) (i) Open Access

\begin{abstract}
Livestock is an important component of food security in many developing nations. However, animal diseases continue to undermine animal production and public health efforts thus widening poverty gap. Unfortunately, the conventional and what seems to be inefficient "top to bottom" disease surveillance and control policies are heavily relied upon such that negative impacts of diseases are underestimated. Participatory disease surveillance (PDS) techniques using semi-structured questioning assisted by key informants targeting focus groups were employed in 60 randomly selected villages of two Nigerian States during the years 2012 to 2014 . Haemagglutination and ELISA tests to detect antibodies to Newcastle disease (ND) were conducted on 950 poultry sera. The status and economic burden of Newcastle disease and the relative livestock populations and some ethno-veterinary practices of these livestock farming communities were brought to the fore. Poultry, goats, cattle, sheep and pigs in descending order were the major livestock species kept in the study areas to which Kendalls Coefficient of Concordance $(W=0.9)$ agreed strongly. Accordingly, ND, lousiness, fowl pox and coccidiosis with percentage scores of ND-52\%, Fowl Pox$31 \%$, lousiness-17\% and Salmonellosis-10\% were important causes of poultry morbidity and mortality. ND sero-prevalence was $39 \%$, relative morbidity; mortality and case fatality rates of $\mathbf{9 5 \%}, \mathbf{7 8 \%}$ and $\mathbf{8 2} \%$ respectively were appraised. Again ND, coccidiosis, ectoparasitism and fowl pox were reported as seasonal poultry diseases $(W=0.6)$. Solanum nodiflorum and Momordica balsalmina were used to treat ND. Major livestock kept, and the ND status and effects in poultry in these livestock farming communities are here reported. Institutionalization of PDS would better
\end{abstract}

\footnotetext{
"Corresponding author.
}

How to cite this paper: Musa, W.I., Lawal, S., Bello, M. and Abdu, P.A. (2016) Participatory Evaluation of the Relative Livestock Populations and the Assessment of the Status and Impacts of Newcastle Disease in Rural Communities of Two Northeastern States, Nigeria. Open Journal of Animal Sciences, 5, 49-58. http://dx.doi.org/10.4236/ojas.2016.61007 
inform strategic livestock policy reforms, and improve national food security and diseases surveillance and reporting system in Nigeria.

\author{
Keywords
}

Participatory, Evaluation, Newcastle Disease, Rural, Communities

\title{
1. Introduction
}

Participatory epidemiology (PE) is an emerging branch of veterinary epidemiology which is based on participatory rural appraisal methods that involve key stakeholders to improve both the understanding as well as developing the best and sustainable options for livestock disease control [1]-[3]. For many years, conventional research methodologies and disease control initiatives that utilized the "top to bottom" approach were faced with limitations to the quality and general acceptability of research outputs in many communities. In many instances human and financial resources available to support conventional disease surveillance efforts are becoming scarce in many developing nations. It has become necessary therefore that identified disease risks should deserve priority for a cost effective and sustainable surveillance which seems to be the basic concept upon which participatory epidemiology is established [1] [2] [4]. Farmers' participation in research is important to understand their priorities for interventions and resource allocations so that solutions developed through this approach would be appropriate to farmers' technical level and culture thus increasing their acceptability and sustainability [5]. With the increasing global focus on one health, emerging and re-emerging zoonoses are better approached by integrating veterinary and public health surveillance programmes offered by participatory concept of disease control.

Local communities are knowledgeable of the principal diseases that affect their livestock, have rich terminology for distinguishing between them, and possess traditional methods of handling them [6]-[8]. For diseases with significant economic impacts, communities have traditional medicaments and often attempt to actively track the evolution of outbreaks and take actions to mitigate risk of further spread. Participatory surveillance taps into these information networks to find out the past and present situations of diseases in order to obtain a better understanding of livestock-keepers knowledge and practices necessary for disease control [9].

Livestock population in a nation is known through census which appears not to be given needed attention in many places. The last time livestock census was conducted in Nigeria, for example, was over 23 years ago and often livestock population is needed in research and planning. Qualitative estimates of livestock populations can easily be obtained at a given time using participator epidemiology tools [9].

Newcastle disease is an infectious virus disease of over 250 bird species that is caused by avian Paramyxovirus seroptype-1 (APMV-1) virus belonging to the genus Avulavirus and considered as one of the major contagious disease of poultry worldwide. ND economic impacts take effects from its worldwide distribution that restricts poultry trade, drop in productivity, mass mortality and financial drain in control measures [10]. In most developing countries, the greatest impact of ND is on rural or backyard chicken production and generally referred to as the most important infectious disease affecting village chickens causing great economic losses [11] [12].

\section{Materials and Methods}

\subsection{Sites Selection}

Bauchi State (HPAI reported) and Gombe State (HPAI not reported) as of December 2014. These states are located in north eastern Nigeria, share boarders and trade in live bird and thus were selected for this study. Muti-stage sampling technique was used to select one LGA from each of the six senatorial districts and simple random sampling technique was also used to select one district from each of the selected LGA of the two states.

\subsection{Collection of Samples}

Ethical clearance to conduct this research was approved by the Ahmadu Bello University Ethical Committee on 
Animal Use. Samples were collected in the months of January to June 2012 and November 2013 to January 2014. Collection of blood from birds was done with birds held laterally with the wing extended to expose the brachial vein and a few small feathers were removed to facilitate viewing of the vein. The vein was wiped with a swab containing $70 \%$ alcohol and a 21 gauge needle attached to a $5 \mathrm{ml}$ syringe inserted into the vein and a maximum of 2 to $3 \mathrm{ml}$ of blood collected. Pressure with a piece of cotton wool was then applied to the vein at the insertion site of the needle until the bleeding stopped. The blood was then transferred to a labeled plain blood collection tube. Samples were allowed to clot at room temperature. The clotted (coagulated) blood was then fractionated by centrifuging at $449 \mathrm{~g}$ for 5 minutes at room temperature $\left(27^{\circ} \mathrm{C}\right)$. After centrifugation, the sera were transferred to labeled two mill screw cap containers and stored in a freezer at $-20^{\circ} \mathrm{C}$ until used.

\subsection{Sample Testing Procedure}

\section{Preparation of $1 \%$ Chicken Red Blood Cell}

Two millilitres of blood was collected from 5-day old chicks and pooled in an equal volume of Alsever's solution. Cells were washed three times in physiological buffered solution ( $\mathrm{pH} 7.2$ ) by centrifuging at $447.2 \mathrm{~g}$ for 5 minutes [13]. One per cent RBC suspension was made by adding $0.9 \mathrm{ml}$ of PBS to $0.1 \mathrm{ml}$ of washed RBC. Antibody titre was determined by haemagglutination inhibition (HI) test using a U bottom microtitre plate [13]. The HI was the highest dilution of serum causing complete inhibition of agglutination of RBC by 4 HAU antigens. The agglutination was assessed by tilting the plates. Only wells in which the RBCs stream at the same rate as the control wells (containing $0.25 \mathrm{ml}$ 1\% RBCs and $0.05 \mathrm{ml} \mathrm{PBS}$ only) were considered to show inhibition.

All sera samples were tested at the Virology and Public Health Laboratories of the Faculty of Veterinary Medicine, Ahmadu Bello University, Zaria using the haemagglutination inhibition test following standard protocol and competitive enzyme linked immunosorbent assay (cELISA) procedures as described by the manufacturers. The Newcastle disease virus antibody ELISA test kits were kindly supplied b AFFINITECH, LTD (USA) and IDVET (France) respectively

\section{Participatory Disease Investigation}

\subsection{Conduct of Interview}

Participation by farmers was made voluntarily but restricted to livestock farmers only. Interview was conducted using semi-structured questioning that was based on a check list/interview guide of written points that explored livestock diseases [14]. The semi-structured interview is a generally accepted interviewing method in PE and rural appraisal that is usually flexible to accommodate the type of information being sought [14]. A check list of steps in the interview was: 1 . Self introduction of all participants with a brief for the purpose of the study. 2. What livestock species were kept in the visited communities? 3. What where the major constraints of livestock. 4. What diseases affected poultry? 5. How were poultry disease managed traditionally? 6 . Was vaccination carried out against most important poultry diseases? 7. What was the impact of vaccination against major poultry disease? 8. Any other relevant issues. Careful observations were made to ensure respondents were relaxed, confident and actively participated. An average of 15 person's focus group discussions was conducted with participants comprising of elders and youths of both genders. Tools and techniques used in this study were as described by Catley, 1997 and AFENET, 2011 [14] [15]. These were generally or specifically used according to particular needs but not predetermined by prescribed PE methodology but were selected based on the information sought.

\subsection{Simple Ranking}

Simple ranking was conducted to get an estimate of livestock specie population. Open ended question (what are the livestock species kept in this area?) requested farmers to mention all livestock species found in the community. Livestock species mentioned were symbolized on pieces of cardboard paper. Farmers were requested to arrange or rank the papers in order in terms of livestock specie population beginning with the highest to the lowest.

\subsection{Proportional Piling}

Proportional piling (PP) was used to relatively estimate livestock species by numbers and their relative impor- 
tance in the communities and to further estimate ND impact following outbreaks [14] [15]. Participants were asked to list the livestock species kept in the community. Circles were drawn on cardboard papers with each circle representing livestock species mentioned within the communities. Participants then allocated 100 counters (beans) (assuming that the livestock population in the community made up a 100\%) to each circles in piles according to the relative numbers of each species with the highest score indicating the most abundant livestock specie in the area. The exercise was repeated to assess livelihood means in the communities, relative incidences of the major livestock diseases and case fatality rates of ND in vaccinated and unvaccinated flocks using the same procedure.

\subsection{Participatory Mapping}

This was drawn before interview began in most communities surveyed [14]. Participants were requested to identify and draw physical features of their community starting with the boundaries and coordinates. Important social (livestock markets, schools, health and veterinary centres, and forests, etc.) and physical features (grazing areas, rivers, centres, and forests, etc.) were identified and drawn in the map.

\subsection{Disease Impact Matrix Scoring}

For the important livestock species mentioned in the community, a matrix was constructed on a cardboard, with benefits derived from those species along the $y$ axis and the important diseases that affect them on the $x$ axis. Participants were given 100 counters and asked to allocate them among the livestock-derived benefits according to the relative importance of each benefit mentioned, with the most important benefit receiving the highest number of counters. The counters for each benefit were then sub-allocated to each disease to show the relative negative impact of each disease on a family's ability to achieve that benefit. In this way the disease having the greatest impact received the highest number of counters. The number of counters allocated for each disease was counted to give a measure of the overall impact of that disease on livestock-derived livelihood means [1] [14] [15].

\subsection{Matrix Scoring for Disease Definition}

The association between diseases based on easily recognizable clinical signs and risk factors was also assessed using matrix scoring method. Simple matrices were constructed on the ground. In the first for poultry, various clinical signs or risk factors formed the $y$ axis and probable diseases, one of which was ND that formed the $x$ axis. For the second and third, the same was done for cattle and then sheep and goats. In all, risk factors or consistent disease clinical signs formed the $y$ axis and probable diseases formed the $x$ axis. For each clinical sign or risk factor, participants allocated 30 counters in proportion to their relative importance for the different diseases [9] [14] [15].

\subsection{Seasonal Calendar}

A horizontal line was drawn and divided into 12 months. Participants were made to divide the year into different seasons paying attention to the characteristics of each season. Where seasonal diseases existed, their relative occurrences were indicated using counters at different points along the line of seasons mentioned. Key risk factors such as rainfall, humidity, vector populations, etc. in relation to disease incidence were also scored. Disease onset, prevalence and seasonality were determined by scoring (PP) using counters. This exercise was continuously debated until all the farmers agreed upon the scores and the actual situation /data were arrived at [9] [14] [15].

\subsection{Traditional/Indigenous Veterinary Knowledge}

The community traditional veterinary knowledge is often related to clinical, epidemiological, gross manifestations of diseases conditions as well as remedies or solutions to livestock production and health. Most times these are known, given literary meanings that may correspond to specific disease entities in various languages and transferred from generations to generations in such communities. Information on these was extracted from livestock farming communities [9] [14] [15]. 


\subsection{Data Analyses}

Data obtained using PE tools were exported to SPSS 2002 version 17.0 where Kendall's coefficient of concordance (W) was used to measure levels of agreement between different informant groups. Kendall's coefficient of concordance measures associations between sets of ranks assigned to objects using values between 0 and 1 . $\mathrm{W}$ ranges from 0 - 1 with 0 denoting no agreement and 1 complete agreement. Agreement may be weak ( $<$ 0.26), moderate ( $\mathrm{W}-$ between 0.26 and 0.38$)$ and good $(\mathrm{W}>0.38)$ [9] [14].

\section{Results}

\subsection{Use of Ranking and Scoring Techniques}

\subsubsection{Proportional Piling and Simple Ranking}

Proportional piling and ranking application as the most popular PE scoring tools indicated crop farming, livestock farming and petit trading to be the most important livelihood activities that the communities were involved. It further identified indigenous poultry, goats, sheep cattle and pigs in order of population as the abundant livestock species kept in the communities as indicated in Table 1. Poultry farmers used PPP and SR to identify Newcastle disease (ND), fowl pox (FP), lousiness (L), and salmonellosis (SM) as important causes of poultry morbidity and mortality (Table 2). Proportional piling for disease impact indicated a mortality estimate of ND outbreaks to be over $70 \%$ in unvaccinated poultry flocks. With vaccination in place, ND mortality estimate was quantified at 30\% (Figure 1 and Figure 2). Proportional piling exercise also revealed the relative occurrence of poultry diseases with ND as the most prevalent (52\%) poultry disease in the study areas (Figure 3).

\subsubsection{Matrix Scoring for Disease Definition}

Farmers recognized ND in chickens to be associated with high morbidity and mortality, was characterized with nervous signs, depression, whitish and sometimes greenish diarrhea. It occurred throughout the year but had higher frequencies of occurrence during the cold windy hamattan.

Table 1. Median scores (95\% CI) of the relative proportions of livestock species kept in selected villages of Bauchi and Gombe States, Nigeria determined through proportional piling exercise.

\begin{tabular}{|c|c|c|c|c|c|c|c|}
\hline \multirow[t]{2}{*}{ State } & \multirow[t]{2}{*}{$\begin{array}{c}\text { Local Government } \\
\text { Area }\end{array}$} & \multirow[t]{2}{*}{ Village } & \multicolumn{5}{|c|}{$\begin{array}{l}\text { Relative livestock } \\
\text { populations }\end{array}$} \\
\hline & & & Poultry & Sheep/goats & Cattle & Pigs & Others \\
\hline \multirow[t]{7}{*}{ Bauchi } & Bauchi & Fadaman & $57(54-60)$ & $40(37-43)$ & $1(0-4)$ & $0(0)$ & $3(0-6)$ \\
\hline & & Wunti & $52(49-55)$ & $33(30-36)$ & $1(0-4)$ & $0(0)$ & $14(11-18)$ \\
\hline & Misau & Luggudi & $58(55-61)$ & $35(32-38)$ & $5(2-8)$ & $0(0)$ & $2(0-5)$ \\
\hline & & legal & $50(47-53)$ & $41(36-42)$ & $8(5-11)$ & $0(0)$ & $1(0-4)$ \\
\hline & katagum & Madangal & $52(49-55)$ & $35(32-38)$ & $11(8-14)$ & $0(0)$ & $2(0-5)$ \\
\hline & & Kakimari & $49(46-52)$ & $48(45-51)$ & $2(0-5)$ & $0(0)$ & $1(0-4)$ \\
\hline & & Mean & 53.0 & 38.7 & 4.7 & 0.0 & 3.8 \\
\hline \multirow[t]{8}{*}{ Gombe } & Gombe & Pantami & $56(53-59)$ & $42(39-45)$ & $1(0-4)$ & $0(0)$ & $1(0-4)$ \\
\hline & & Malam inna & $53(50-56)$ & $36(33-39)$ & $8(5-11)$ & $0(0)$ & $3(0-6)$ \\
\hline & Yamaltu deba & Deba & $49(46-52)$ & $33(30-36)$ & $9(6-12)$ & $2(0-5)$ & $7(4-10)$ \\
\hline & & Kwadon & $60(57-63)$ & $33(30-36)$ & $5(2-8)$ & $0(0)$ & $2(0-5)$ \\
\hline & Kaltungo & Kalaring & $48(45-51)$ & $32(29-35)$ & $8(5-11)$ & $3(0-6)$ & $9(6-12)$ \\
\hline & & Ture-mai & $49(46-52)$ & $36(33-39)$ & $10(7-13)$ & $1(0-4)$ & $4(1-7)$ \\
\hline & & Mean & 52.5 & 35.3 & 6.8 & 1.0 & 4.3 \\
\hline & & Overall mean & 52.8 & 37.0 & 5.75 & 0.5 & 5.9 \\
\hline
\end{tabular}




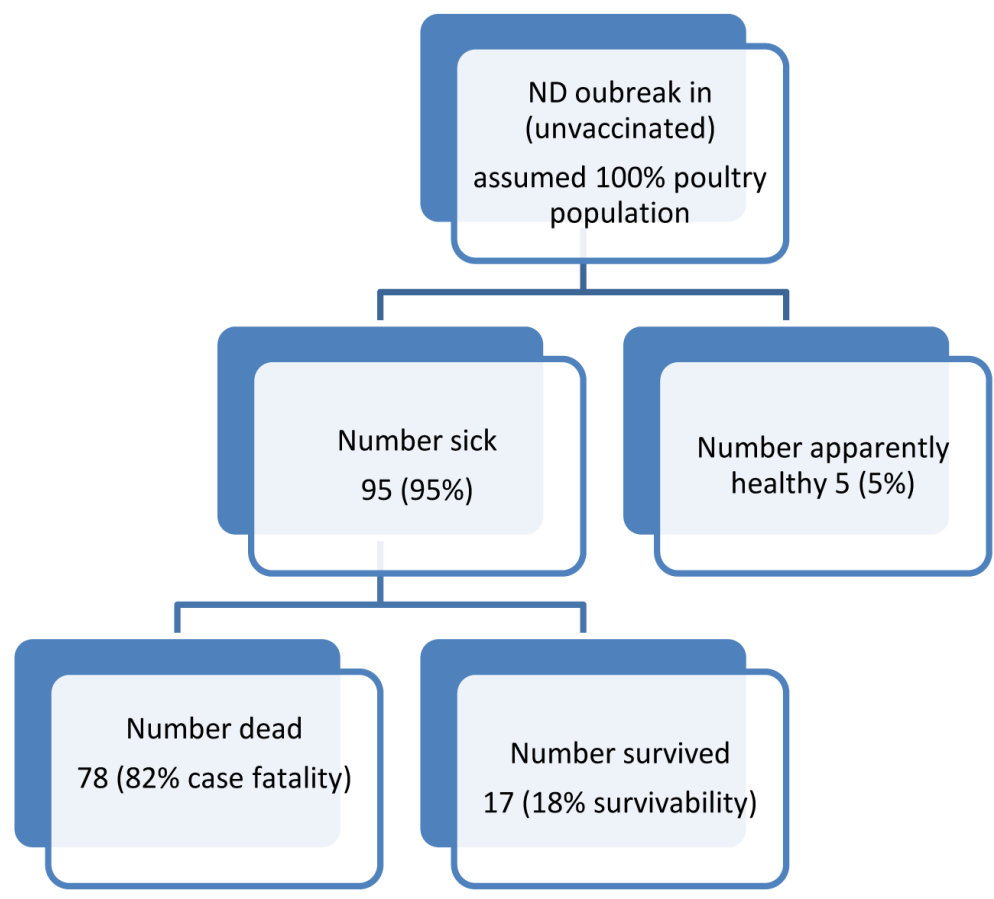

Figure 1. Farmers' perception of the relative impact of the outbreak of Newcastle disease in unvaccinated naïve poultry flock.

Table 2. A summary of matrix scoring (by proportional piling of 30 counters each) of major poultry diseases versus clinical manifestations as reported by rural poultry farmers in seven selected villages of Bauchi and Gombe States, Nigeria.

\begin{tabular}{|c|c|c|c|c|}
\hline \multirow[t]{2}{*}{ Clinical attribute } & \multicolumn{3}{|c|}{ Disease } & \multirow[b]{2}{*}{ Ectoparasitism } \\
\hline & Newcastle disease & coccidiosis & Fowl pox & \\
\hline High morbidity $(\mathrm{W}=0.83)$ & $18(15-21)$ & $3(0-6)$ & $3(0-6)$ & $8(5-11)$ \\
\hline High mortality $(\mathrm{W}=0.90)$ & $20(17-23)$ & $8(5-11)$ & $1(0-4)$ & $1(0-4)$ \\
\hline Nervous signs $(\mathrm{W}=0.83)$ & $27(24-30)$ & $0(0-0)$ & $0(0-0)$ & $3(0-6)$ \\
\hline Respiratory distress $(\mathrm{W}=0.90)$ & $27(24-30)$ & $0(0-0)$ & $2(0-2)$ & $1(0-1)$ \\
\hline Greenish diarrhea $(\mathrm{W}=0.51)$ & $28(25-30)$ & $1(0-1)$ & $1(0-1)$ & $0(0-0)$ \\
\hline Bloody diarrhea $(\mathrm{W}=0.54)$ & $2(0-2)$ & $28(25-30)$ & $0(0-0)$ & $0(0-0)$ \\
\hline Whitish diarrhea (W 0.90) & $27(24-30)$ & $0(0-0)$ & $0(0-0)$ & $2(0-2)$ \\
\hline Papules/nodules $(\mathrm{W}=0.54)$ & $0(0-0)$ & $0(0-0)$ & $27(24-30)$ & $2(0-2)$ \\
\hline Insects on the body $(\mathrm{W}=0.83)$ & $0(0-0)$ & $0(0-0)$ & $2(0-2)$ & $2(0-2)$ \\
\hline Decrease productivity $(\mathrm{W}=0.90)$ & $15(12-18)$ & $6(3-9)$ & $7(4-10)$ & $2(0-2)$ \\
\hline Vector associated $(\mathrm{W}=0.83)$ & $2(0-2)$ & $0(0-0)$ & $6(3-9)$ & $22(19-25)$ \\
\hline
\end{tabular}

\subsubsection{Disease Impact Matrix Scoring}

This was studied based on the economic values of various livestock species in one of the visited communities. It clearly indicated poultry as the major source of egg, meat and emergency source of fund.

\subsubsection{Semi-Structured Interview}

The use of semi-structured interview (SSI) showed that most livestock and especially poultry were predominantly kept on free range with little or no veterinary care and feed supplementations. 


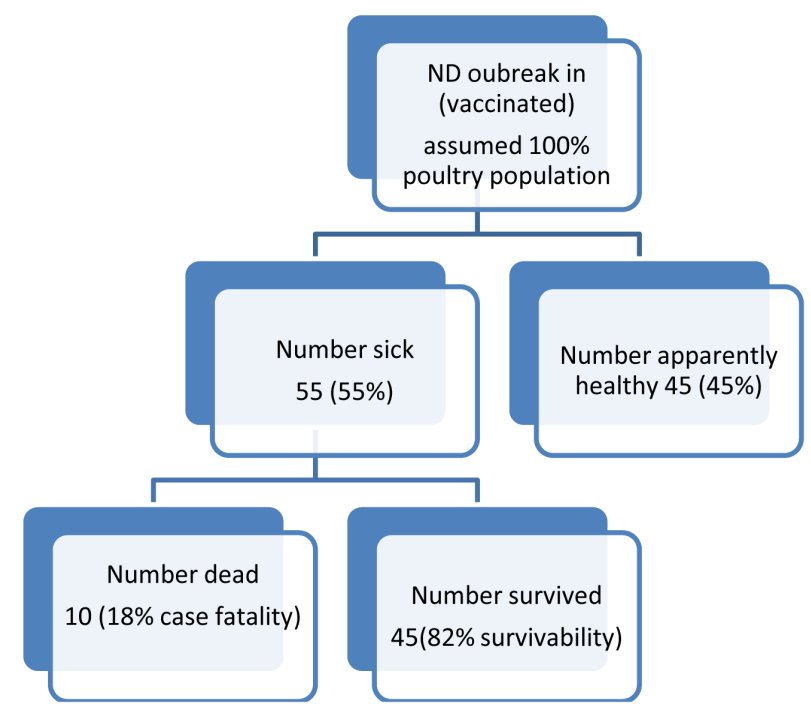

Figure 2. Farmers' perception of the relative impact of the outbreak of Newcastle disease in vaccinated poultry flock.

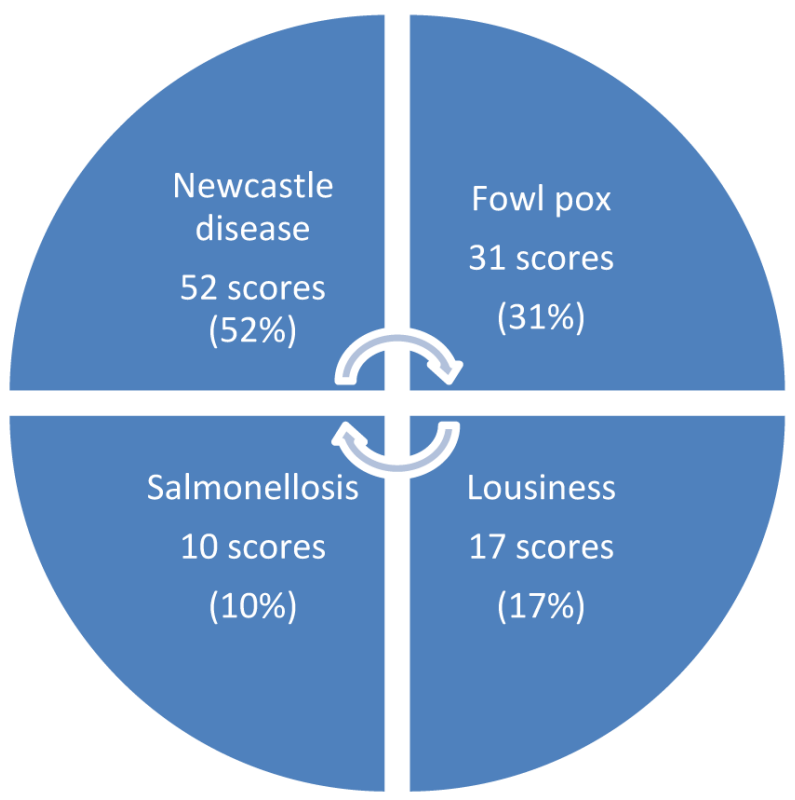

Figure 3. Proportional piling (scores) to indicate the relative occurrence of various poultry diseases.

\subsection{Use of Visualization Technique}

\subsubsection{Seasonal Calendar}

Seasonal calendar puts the year into 4 recognizable local seasons kaka (harvest period/early dry season), bazara/hamattan (cold dry windy season), zafi (hot season) and damina (rainy season). ND, though occurred all year round, was most common during the cold hamattan period. Lousiness was most common just before the onset of rains while pox was most common with early rains.

\subsubsection{Participatory Mapping}

This exercise involved both the literate and illiterate farmers by identifying on the community map the positioning of social amenities as well as natural features of the communities. 


\subsection{Ethnoveterinary Knowledge}

Traditionally, gautankaji (Solanum nodiflorum), gunan bera (Momordica balsalmina) were used as remedies for ND in the villages visited. Palm and engine oils were commonly used to treat lousiness and fowl pox.

\subsection{Sero-Prevalence Study}

An overall sero-prevalence of ND in both States was 39\% with the highest prevalence of $60 \%$ in northern Gombe (Table 3).

\section{Discussion}

Extensive researches have been conducted using PE tools in recent years; also reviews focusing on the usage of PE by Veterinarians that led to the reliability and validity of information obtained [2] [3] [15]. Participatory rural appraisal is now known for its problem solving methodology that allows experts to learn about traditional knowledge systems and community development priorities [16] in many rural communities of the world, priority livestock diseases were established and practical control measures instituted through PDS [17]-[21]. In this study, common poultry diseases with the most important being ND were appraised in various communities. Traditional management of ND was emphasized in all visited communities. As a trial in 2009/2010, Nigeria chose to use PE practitioners trained by the EDRSAIA project to investigate the status of priority livestock diseases in five geopolitical regions of the country. The PS team in addition to the targeted diseases diagnosed PPR in Nigeria, which led to an effective emergency PPR disease control program [22]. PDS therefore has an additional advantage of unveiling other diseases not initially targeted.

Of all the livestock populations' poultry was ranked first within all the visited communities. It was reasoned that there was hardly any house without at least a chicken in the rural areas. Poultry was easy to start and maintained, it was a source of quick money to solve pressing needs and was frequently used for religious and spiritual celebrations, and as gifts to friends and visitors so it became a community pride to own chickens.

During ranking and scoring, ND was placed the most economically significant poultry disease in these farming communities. It is well established that ND is a pandemic and that its impact is felt by every poultry farmer worldwide, thus it was given local names in traditional settlements worldwide, disease impact matrix scoring strongly showed the likelihood of ND outbreaks to invariably affect egg and meat consumption and ultimately

Table 3. Newcastle disease sero-prevalence in poultry and wild birds from six senatorial districts of Bauchi and Gombe States using ELISA and haemagglutination inhibition (HI) test.

\begin{tabular}{|c|c|c|c|c|c|c|}
\hline & \multicolumn{5}{|c|}{ State } & \\
\hline & \multicolumn{2}{|l|}{ Bauchi } & & \multicolumn{3}{|c|}{ Gombe } \\
\hline & \multicolumn{5}{|c|}{ Region } & \\
\hline & North & Central & South & North & Central & South \\
\hline Sera samplesa tested $(n=950)$ & 164 & 170 & 166 & 150 & 150 & 150 \\
\hline ELISA positive $(\mathrm{n}=170)$ & 34 & 60 & 36 & 100 & 40 & 70 \\
\hline HI positive & 58 & 66 & 56 & 90 & 40 & 56 \\
\hline ELISA seroprevalence (\%/region) & 20.7 & 35.3 & 21.6 & 66.7 & 26.6 & 46.7 \\
\hline HI seroprevalence (\%/region) & 35.4 & 38.8 & 33.7 & 60.0 & 26.6 & 37.3 \\
\hline ELISA seroprevalence (\%/state) & & 26.0 & & & 46.7 & \\
\hline HI seroprevalence (\%/state) & & 36.0 & & & 41.3 & \\
\hline Overall ELISA both states seroprevalence (\%) & & & 35.8 & & & \\
\hline Overall HI both states seroplrevalence (\%) & & & 38.5 & & & \\
\hline
\end{tabular}

Key: ELISA-enzyme linked immunosorbent assay, n-number of birds sampled, HI-haemagglutination inhibition 
quick source of money to solving emergency family needs in many rural communities of Nigeria. [10]-[12]. The high sero-prevalence (38\% - 60\%) of ND in all communities studied indicates clearly the endemic nature as well as the wide spread of ND. In Indonesia for instance, participatory disease surveillance and response (PDSR) was successfully used targeting village poultry production system to report evidence of ND virus circulation and apparent absence of HPAI. This information was used to target ND control [23]. Furthermore, participatory disease investigation makes use of traditional knowledge, historical information and extensive oral communication network making it a more reliable and sensitive clinical surveillance [3] [9] [14]-[16] [24]. The traditional veterinary knowledge is concerned with history and patterns of diseases in an area. The local communities often recognize the principal diseases that affect their livestock and have a rich terminology for distinguishing between them [3]. Though this study targeted ND, fowl pox, lousiness and salmonellosis were found to be important poultry diseases in the rural communities studied (Figure 3 ) which opens a new horizon to holistic control of poultry diseases in rural communities who seem to hold over $65 \%$ of total poultry populations in many developing nations [8] [11]. Some of the matrix scoring findings in this study showed ND to be associated with high morbidity, mortality and occurred year round with higher incidences in the cold windy hamattan. The information that ND occurred with high incidence during hamattan may assist farmers as well as livestock policy makers to initiate appropriate ND control measures especially vaccinating birds and avoiding introduction of new birds before the onset of hamattan. It further elucidates the fact that ND outbreaks will directly affect most needed animal protein intake as well as settlement of emergency fees such as school fees in many rural communities in northeastern Nigeria. The results of matrix scoring (Table 2) showed that farmers usually recognize ND by nervous signs, whitish diarrhoea, high morbidity and mortality which agree with some established literatures [8] [10] [11]. In many literatures however, greenish diarrhoea especially in acute ND infections supersedes the white diarrhoea reported by farmers [10] [11]. This means that farmers may lack the ability to recognize acute ND that may not be associated with the normal nervous signs and high mortality and most especially may lack the ability to recognize HPAI therefore limiting their ability to report suspected cases. Matrix scoring further made it possible to evaluate certain disease syndromes like "makere (somnolence), fakat (massive death), and farin kasha (white diarrhea)" to mean ND as understood by the Hausas and this seems to agree with the clinical presentations of ND as existed in many scientific findings on ND [8] [10] [11].

The major limitations in the conduct of participatory research especially in the livestock subsector and particularly in Nigeria are willingness of target farmers to participate in the absence of incentives and also participants tend to look at the study from a political perspective. These may likely affect the validity of results obtained.

\section{Conclusion}

A sustainable and workable livestock disease surveillance system should have a perceived benefit to data providers. Participatory epidemiology in view of this ensured animal health researchers and famers benefited from oral information exchange and arrived at reliable and sustainable intervention strategies.

\section{References}

[1] Jost, C.C., Mariner, J.C., Roeder, P.L., Sawitri, E. and Macgregor-Skinner, G.J. (2007) Participatory Epidemiology in Disease Surveillance and Research. Review Science Technical Office International des Epizootics, 26, 537-549.

[2] Catley, A. (2005) Participator Epidemiology: A Guide for Trainers. African Union/Interafrican Bureau for Animal Resources, Nairobi, 1-18.

[3] Catley, A., Alders, R.G. and Wood, J.L.N. (2012) Participatory Epidemiology: Approaches, Methods, Experiences. The Veterinary Journal, 191, 151-160. http://dx.doi.org/10.1016/j.tvjl.2011.03.010

[4] Mariner, J.C., Hendrickx, S., Pfeiffer, D.U., Costard, S., Knopf, I., Okuthe, D., Chibeu, D., Parmley, J., Musenero, M., Pisang, C.J., Zingeser., B.A., Jones, S.N., Ali, B., Bett, M.M., Araba, F.A., Mehta, P. and Jost, C.C. (2011) Integration of Participatory Approaches into Surveillance Systems. Review Science Technical Office International des Epizootics, 3, 653-659.

[5] Apantaku, S.O. (2006) Analysis of Participation of Farmers in Participatory Poultry Production Research in Lagos State, Nigeria. Livestock Research for Rural Development, 18, 1-12.

[6] Catley, A., Okoth, S., Osman, J., Fison, T., Njiru, Z., Mwangi, J., Jones, B.A. and Leyland, T.J. (2001) Participatory Diagnosis of a Chronic Wasting Disease in Cattle in Southern Sudan. Preventive Veterinary Medicine, 51, 161-181. http://dx.doi.org/10.1016/S0167-5877(01)00240-9

[7] Musa, I.W., Ndahi, M., Pam, E.G., Okike, A., Cyrile, P.C., Saskia, H. and Jost, C. (2013) Using Participatory Epidemiological Techniques to Establish Rural Based Poultry Disease Profile; Practical Field Experience in the Jos Plateau, 
Nigeria. World Poultry Science Journal, 69, 387-400. http://dx.doi.org/10.1017/S0043933913000378

[8] Musa, I.W. and Kaltungo, B.Y. (2014) Participatory Methods in the Profiling of Livestock Diseases in the Jos Plateau, Nigeria. Animal and Veterinary Sciences, 2, 154-160. http://dx.doi.org/10.11648/j.avs.20140205.15

[9] Mariner, J.C. and Paskin, R. (2000) Food and Agricultural Organisation. Manual on Participatory Epidemiology, Methods for the Collection of Action-Oriented Epidemiological Intelligence, 5-81.

[10] Alexander, D.J. (1995) The Epidemiology and Control of Avian Influenza and Newcastle Disease. Comparative Pathology, 112, 105-126. http://dx.doi.org/10.1016/S0021-9975(05)80054-4

[11] Spradbrow, P.B. (1993) Newcastle Disease in Village Chickens. Poultry Science Reviews, 5, 57-96.

[12] Aini, I., Ibrahim, A.L. and Spradbrow, P.B. (1990) Vaccination of Chickens against Newcastle Disease with a Food Pellet Vaccine. Avian Pathology, 19, 371-384. http://dx.doi.org/10.1080/03079459008418687

[13] Collee, J.G., Duguid, J.P., Fraser, A.G. and Marmion, B.P. (1982) Practical Medical Microbiology. 13th Edition, Mackie and McCartey, Eds., Churchill Livingstone, 37-39.

[14] African field epidemiology network (AFFENET) (2011) Public Health Participatory Epidemiology. Introductory Training Module, Manual for Trainers, 120-210.

[15] Catley, A.P. (1997) Adapting Participatory Appraisal for the Veterinary Epidemiologist: Participatory Appraisal Tools for Use in Livestock Disease Data Collection. Proceedings of the Society for Veterinary Epidemiology and Preventive Medicine, Chester, United Kingdom, 4-9.

[16] Chambers, R. (2007) From PRA to PLA and Pluralism: Practice and Theory. IDS Working Paper 286, July 2007.

[17] Mariner, J.C., Manzoor Hussain, Rodder, P.L. and Catley, A. (2003) Use of Participatory Disease Searching in Pakistan for Rinderpest and More (Vina del Mar, Chile). Proceedings of the $10^{\text {th }}$ International Symposium on Veterinary Epidemiology and Economics, Rome, November 2003, 23.

[18] Admassu, B. (2005) The Participatory Epidemiological Investigation of FMD in Erzurum Province. http://www.participatoryepidemiology.info/userfiles/Admassu-FAO-Turkey-PE.pdf

[19] Catley, A., Chibunda, R.T., Ranga, E., Makungu, S., Magayane, F.T., Magoma, G., Madege, M.J. and Vosloo, W. (2004) Participatory Diagnosis of a Heat-Intolerance Syndrome in Cattle in Tanzania and Association with Footand-Mouth Disease. Preventive Veterinary Medicine, 65, 17-30. http://dx.doi.org/10.1016/j.prevetmed.2004.06.007

[20] Hussain, M., Afzal, M., Ali, Q., Taylor, W., Mariner, J. and Roeder, P. (2008) The Epidemiology of Peste Des Petits Ruminants in Pakistan and Possible Control Policies. Revue Scientifique et Technique, 27, 869-876.

[21] Jost, C.C., Nzietchueng, S., Kihu, S., Bett, B., Njogu, G., Swai, E.S. and Mariner, J.C. (2010) Epidemiological Assessment of the Rift Valley Fever Outbreak in Kenya and Tanzania in 2006 and 2007. American Journal of Tropical Medicine and Hygiene, 83, 65-72. http://dx.doi.org/10.4269/ajtmh.2010.09-0290

[22] Mohamadou, F., Jost, C. and Ihedioha, J. (2011) Financial Costs of Disease Burden, Morbidity and Mortality from priority Livestock Diseases in Nigeria. Nigeria Integrated Animal and Human Health Project. International Livestock Research Institute, Nairobi, 6-20.

[23] Muhammad, J.W. and Resti, Y. (2010) The Clinical Profiles of Avian Influenza in Endemic and Non-Endemic Regions of Indonesia. Hospital-Based Studies and Its Implication on Clinical Management in the Future. Indonesian Journal of Tropical and Infectious Diseases, 1, 114-117.

[24] Mariner, J.C. and Roeder, P.L. (2003) Use of Participatory Epidemiology in Studies of the Persistence of Lineage 2 Rinderpest Virus in East Africa. Veterinary Record, 152, 641-647. http://dx.doi.org/10.1136/vr.152.21.641 